\title{
Analisis Faktor yang Mempengaruhi Implementasi Pelayanan Kefarmasian Puskesmas di Kota Semarang
}

\author{
Analysis of Factors Affecting the Implementations of Pharmacy Services at \\ Health Center in Semarang City
}

\author{
Aprilia Indah Pratiwi ${ }^{*}$, Achmad Fudholi ${ }^{2}$, Satibi ${ }^{2}$ \\ 1 Mahasiswa S2 Ilmu Farmasi, Universitas Gadjah Mada \\ ${ }^{2}$ Fakultas Farmasi, Universitas Gadjah Mada \\ Corresponding author: Aprilia Indah Pratiwi: Email: Apriliaindah.pratiwi@yahoo.com \\ Submitted: 24-26-2019 \\ Revised: 16-07-2019 \\ Accepted: 16-07-2019
}

\begin{abstract}
ABSTRAK
Standar pelayanan kefarmasian yang digunakan di Puskesmas yaitu Permenkes Nomor 74 Tahun 2016. Penelitian ini bertujuan untuk mengetahui implementasi pelayanan kefarmasian Puskesmas di Kota Semarang, mengetahui perbedaan peran SDM farmasi, ketersediaan anggaran dan tipe puskesmas, mengidentifikasi faktor pendukung dan penghambat pelayanan kefarmasian Puskesmas di Kota Semarang serta merumuskan solusi mengatasi permasalahan dalam pelayanan kefarmasian. Metode penelitian yang digunakan merupakan observasional deskriptif kuantitatif melalui pendekatan cross sectional pada 36 Puskesmas di Kota Semarang. Periode pengambilan data dilakukan pada bulan Oktober s/d Desember 2018 dengan cara observasi langsung dan wawancara terhadap penanggungjawab unit pelayanan farmasi. Analisa statistik menggunakan Uji Independent Sample T-Test. Selanjutnya dilakukan identifikasi faktor pendukung, penghambat dan perumusan solusi menggunakan Basic Priority Rating Scale. Hasil penelitian menunjukan bahwa Secara umum pelayanan kefarmasian Puskesmas di Kota Semarang dapat dikategorikan sangat baik dengan nilai rata-rata 83,56 $\pm 6,24$. Seluruh Puskesmas Kota Semarang sudah melakukan kegiatan pengelolaan sediaan farmasi dan BMHP (Aspek manajerial) dengan nilai rata-rata 64,64 $\pm 4,409$. Pelayanan farmasi klinik sudah dilakukan oleh apoteker dan tenaga teknis kefarmasian walaupun belum sepenuhnya dengan nilai rata-rata $18,92 \pm 2,419$. Terdapat perbedaan yang signifikan untuk peran SDM farmasi dan tipe Puskesmas dalam pelayanan kefarmasian Puskesmas di Kota Semarang dengan (p: 0,000) Dukungan Kepala Puskesmas dan koordinasi yang baik merupakan faktor pendukung. Faktor-faktor yang menghambat adalah apoteker belum tersedia di semua Puskesmas, kurangnya pelatihan untuk tenaga farmasi dalam pelayanan farmasi klinik, sarana dan prasarana serta kelengkapan Standar Operasional Prosedur (SOP). Solusi dengan perbaikan sarana dan prasarana, membuat SOP pelayanan farmasi klinik, usulan anggaran untuk penambahan apoteker, pembinaan, monitoring dan evaluasi pelayanan farmasi klinik.
\end{abstract}

Kata kunci: Pelayanan Kefarmasian; SDM; Anggaran; Tipe Puskesmas

\section{ABSTRACT}

Pharmaceutical service standards used in health center are Permenkes No. 74 of 2016. This study aims to determine the implementation of health center pharmacy services in Semarang City, to know the different roles of pharmaceutical human resources, budget availability and types of health center, identify supporting factors and inhibit the services of pharmacy in Semarang and formulate solutions to overcome problems in pharmaceutical services. The research method used was descriptive quantitative observational through a cross sectional approach at 36 health centers in the city of Semarang. The data collection period is conducted from October to December 2018 by direct observation and interviews with the person in charge of the pharmaceutical service unit. Statistical analysis using the Independent Sample T-Test. Furthermore, identification of supporting factors, inhibitors and formulation of solutions was carried out using the Basic Priority Rating Scale. The results showed that in general the pharmacy services of health center in Semarang city can be categorized very well with an average value of $83.56 \pm 6.24$. The most health centers in Semarang city have carried out management activities for pharmaceutical preparation and BMHP (managerial aspects) with an average value of $64.64 \pm 4.409$. Clinical pharmacy services have been carried out by 
pharmacists and pharmaceutical technical personnel although not yet fully with an average value of $18.92 \pm 2.419$. There are significant differences for the role of pharmaceutical human resources and the type of Health center in pharmacy services in health center in Semarang city with (p: 0,000) Head Health Center support and good coordination are supporting factors. The inhibiting factors are that pharmacists are not yet available in all Puskesmas, lack of training for pharmaceutical personnel in clinical pharmacy services, facilities and infrastructure as well as complete Standard Operating Procedure (SOP). Solutions with improvements to facilities and infrastructure, making SOP clinical pharmacy services, proposed budgets for the addition of pharmacists, guidance, monitoring and evaluation of clinical pharmacy services.

Keywords: Pharmaceutical Services; human resources; Budget; Type of Puskesmas

\section{PENDAHULUAN}

Puskesmas sebagai FKTP mempunyai peran strategis dan terlaksananya JKN dibandingkan dengan praktik dokter, dan klinik swasta. Hal ini disebabkan karena penyelenggaraan puskesmas yang berdasarkan prinsip paradigma sehat, pertanggungjawaban wilayah, kemandirian masyarakat, pemerataan, teknologi tepat guna serta keterpaduan dan kesinambungan sehingga puskesmas berfungsi sebagai pusat penggerak pembangunan berwawasan kesehatan, pusat pemberdayaan masyarakat dan pusat pelayanan kesehatan strata pertama (Rahma dkk., 2016).

Pelayanan kefarmasian merupakan kegiatan yang terpadu dengan tujuan untuk mengidentifikasi, mencegah dan menyelesaikan masalah obat dan masalah yang berhubungan dengan kesehatan. Pelayanan kefarmasian di Puskesmas meliputi dua kegiatan, yaitu kegiatan yang bersifat manajerial berupa pengelolaan obat dan Bahan Medis Habis Pakai dan kegiatan pelayanan farmasi klinik (Kemenkes RI., 2016). Pengelolaan obat di puskesmas merupakan salah satu indikator mutu pelayanan kefarmasian. Sistem pengelolaan obat, BMHP, dan alkes (Quick dkk., 2012) terdiri atas seleksi, pengadaan, distribusi dan penggunaan obat, BMHP dan alkes.

Pengelolaan obat, BMHP, dan alkes dipengaruhi oleh kualitas sumber daya manusia, fasilitas, perlengkapan, biaya/harga, administrasi, dan sistem informasi. Sumber daya manusia, keuangan, sarana dan prasarana merupakan faktor internal yang mempengaruhi kinerja Apoteker, sehingga berdampak pada mutu pelayanan kefarmasian (Daulay dkk., 2018). Kekurangan tenaga kefarmasian terutama Apoteker salah satu kendala dalam pelayanan kefarmasian Puskesmas di Kota Semarang, yaitu dari 37 Puskesmas hanya 16 Puskesmas yang memiliki Apoteker. Sehingga penempatan Apoteker diutamakan untuk
Puskesmas Rawat Inap. Selain itu, pemanfatan anggaran lebih diutamakan untuk kegiatan yang bersifat menejerial. Hal ini mendorong peneliti untuk melakukan penelusuran dan tindak lanjut dalam rangka ingin mengetahui faktor pendukung dan penghambat peranan SDM farmasi, ketersediaan anggaran dan tipe puskesmas dalam implementasi pelayanan kefarmasian Puskesmas di Kota Semarang.

\section{METODE}

Metode penelitian yang digunakan merupakan observasional deskriptif analitis melalui pendekatan cross sectional pada 36 Puskesmas di Kota Semarang. Pengambilan sample dilakukan dengan observasi langsung terhadap penanggungjawab pelayanan farmasi dan wawancara terhadap 16 orang Apoteker dan 20 orang Tenaga Teknis Kefarmasian (TTK) serta 36 Kepala Puskesmas untuk menggali faktor pendukung dan penghambat implementasi pelayanan kefarmasian Puskesmas di Kota Semarang pada bulan Oktober s/d Desember 2018. Analisa statistik menggunakan Uji Independent Sample T-Test. Selanjutnya dilakukan identifikasi faktor pendukung, penghambat dan perumusan solusi menggunakan Basic Priority Rating Scale untuk meningkatkan pelayanan kefarmasian Puskesmas di Kota Semarang.

\section{HASIL DAN PEMBAHASAN}

Jumlah responden adala 36 penanggung jawab farmasi di Puskesmas terdiri 1 (satu) lakilaki $(2,8 \%)$ dan 35 perempuan $(97,2 \%)$. Usia responden antara 20-30 tahun sebanyak 4 orang $(11,1 \%), 31-40$ tahun sebanyak 12 orang (33,3\%), 41-50 tahun sebanyak 17 orang (47,2\%) dan 51-58 tahun sebanyak 3 orang $(8,3 \%)$. Tingkat pendidikan responden adalah SAA/SMK Farmasi sebesar 2,8\%, D3/S1 Farmasi sebesar 52,8\% dan apoteker sebesar 44,4\%. Jam praktik responden semuanya $\geq 6$ jam perhari. 
Tabel I. Skor Implementasi Pelayanan Kefarmasian Puskesmas di Kota Semarang Tahun 2018

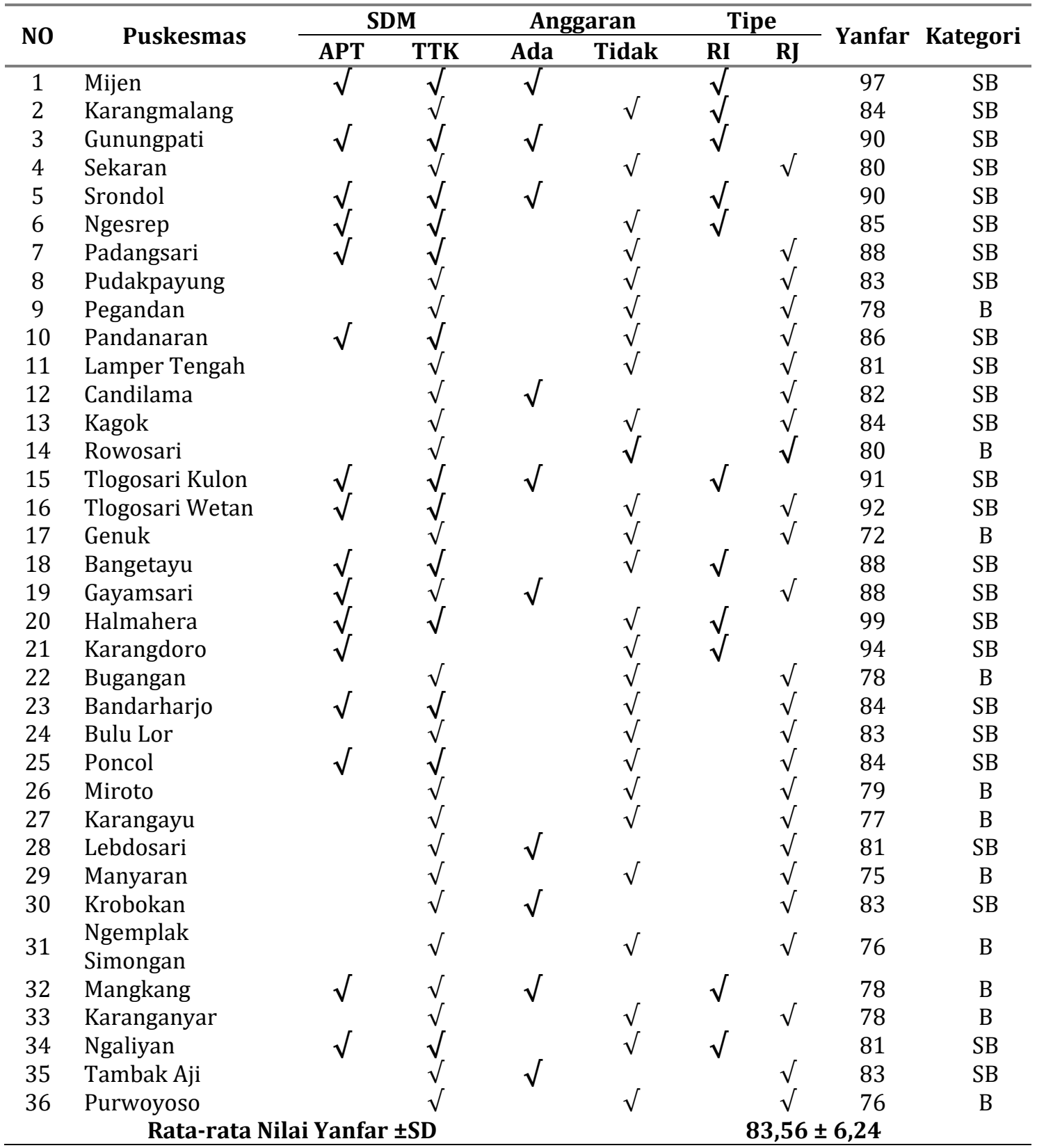

Keterangan : TTK = Tenaga Teknis Kefarmasian (D3/S1 Farmasi); RI = Rawat Inap; RJ = Rawat Jalan; SB = Sangat Baik; B = Baik

Puskesmas di Kota Semarang tidak semuanya mempunyai Apoteker, hanya 16 Puskesmas yang mempunyai Apoteker. Pelayanan farmasi klinik belum semua dilakukan oleh Apoteker dan tenaga teknis kefarmasian Puskesmas di Kota Semarang.

Secara umum pelayanan kefarmasian Puskesmas di Kota Semarang dapat dikategorikan sangat baik dengan nilai rata-rata 83,56 \pm 6,24. Seluruh Puskesmas di Kota Semarang sudah melakukan kegiatan pengelolaan sediaan farmasi dan BMHP. Proses dispensisng yang dilakukan yaitu mulai dari meracik obat setelah dilakukan skrinning resep, memberikan label dan etiket, penyerahan obat disertai dengan pemberian informasi serta 
Tabel II. Karakteristik Pelayanan Farmasi Klinik di Puskesmas Kota Semarang Tahun 2018

\begin{tabular}{clcc}
\hline No & Pelayanan Farmasi Klinik & $\mathbf{N}$ & $\mathbf{\%}$ \\
\hline 1 & Pengkajian Resep & 36 & 100 \\
2 & Peracikan dan Penyerahan Resep & 36 & 100 \\
3 & Pemberian Informasi dan terdokumentasi & 36 & 100 \\
4 & Pemberian Konseling dan terdokumentasi & 16 & 44,44 \\
5 & Home pharmacy care & 8 & 22,22 \\
6 & Melakukan MESO & 29 & 80,56 \\
7 & Visite & 11 & 30,56 \\
\hline
\end{tabular}

Keterangan: $\mathrm{n}=$ Frekuensi; \%= Persentase

pendokumentasian dengan nilai rata-rata 64,64 $\pm 4,409$.

Pelayanan farmasi klinik sudah dilakukan oleh apoteker dan tenaga teknis kefarmasian walaupun belum sepenuhnya dengan nilai ratarata $18,92 \pm 2,419$. Kegiatan farmasi klinik yang dilakukan mencakup Pengkajian resep (administrasi, farmasetik, klinis), Peracikan dan Penyerahan Resep, Pemberian informasi dan terdokumentasi, Pemberian konseling dan terdokumentasi, Home pharmacy care, Melakukan MESO dan Visite. Pengkajian, peracikan dan penyerahan resep telah dilakukan pada seluruh Puskesmas (100\%). Penyerahan obat disertai dengan pemberian informasi obat yang meliputi aturan pakai, lama pengobatan, cara pakai, efek samping, interaksi obat dan cara penyimpanan obat. Konseling hanya dilakukan pada Puskesmas yang memiliki Apoteker yaitu sebanyak 16 Puskesmas $(44,44 \%)$. Visite hanya dilakukan di Puskesmas Rawat Inap $(30,56 \%)$ dan hanya 8 Puskesmas $(22,22 \%)$ yang telah melakukan home pharmacy care serta Puskesmas melakukan MESO yaitu hanya $80,56 \%$. Kondisi ini disebabkan karena kurangnya tenaga, pengetahuan dan keterampilan dari tenaga farmasi yang ada, serta beban tugas yang berat seperti banyaknya laporan yang harus disiapkan untuk dikirim ke Dinas Kesehatan. Keterbatasan kehadiran apoteker dikarenakan ada pekerjaan pokok diluar apotek, kekurangan skill berupa manajemen, dan komunikasi, serta tidak ada ruang layanan konseling dan keterbasan jumlah SDM farmasi (Mulyagustina dkk., 2017). Pelayanan farmasi klinik belum maksimal dilakukan oleh tenaga kefarmasian yang ada di puskesmas PONED, dikarenakan keterbatasan tenaga, waktu, ruang gerak, pengetahuan dan kesempatan (Hendri dkk., 2018).
Hasil perhitungan regresi linier pengaruh aspek menejerial terhadap pelayanan farmasi klinik diperoleh nilai sig 0,00 lebih kecil dari 0,05 artinya bahwa aspek manajerial pelayanan kefarmasian Puskesmas di Kota Semarang mempengaruhi pelayanan farmasi klinis Puskesmas yang diberikan sebesar 48,59\%. Kualitas pelayanan farmasi klinis menurun sebesar 3,784 point apabila aspek menejerial tidak terpenuhi. Aspek manajerial yang mungkin berpengaruh terhadap pelayanan farmasi klinis yang diperoleh dari observasi langsung di Puskesmas Kota Semarang diantaranya, keberadaan Apoteker, sarana dan prasarana (misal : ruang konseling), SOP dan ketersediaan anggaran untuk pelayanan farmasi klinik. Kurangnya informasi tambahan (poster, spanduk, leaflet, dll) tentang obat, kurangnya tenaga kefarmasian ini menjadi faktor utama penyebab tidak tersedianya prosedur tetap yang lengkap, karena umumnya kekurangan informasi terhadap prosedur tetap pelayanan bahkan tidak tahu menahu tentang prosedur tetap pelayanan kefarmasian yang semestinya dijalankan di Puskesmas (Herman dkk., 2013).

Belum semua Puskesmas di Kota Semarang memiliki jenis dan jumlah tenaga kefarmasian yang mencukupi, sehingga berpengaruh terhadap pelayanan kefarmasian yang diberikan. Kurangnya jumlah tenaga kesehatan di puskesmas, menjadikan beban kerja tenaga kesehatan puskesmas semakin tinggi dan tidak sesuai dengan tupoksi serta latar belakang pendidikannya. Sehingga pada akhirnya berdampak pada menurunnya kualitas pelayanan puskesmas. Untuk itu perlu dilakukan manajemen SDM yang nyata dan komprehensif (Lestari dkk., 2014).

Hasil uji Independent Sample $T$ Test diperoleh nilai signifikasi $0,000<0,05$ dengan 
Tabel III. Pengaruh Aspek Manajerial Terhadap Pelayanan Farmasi Klinik Puskesmas di Kota Semarang Tahun 2018

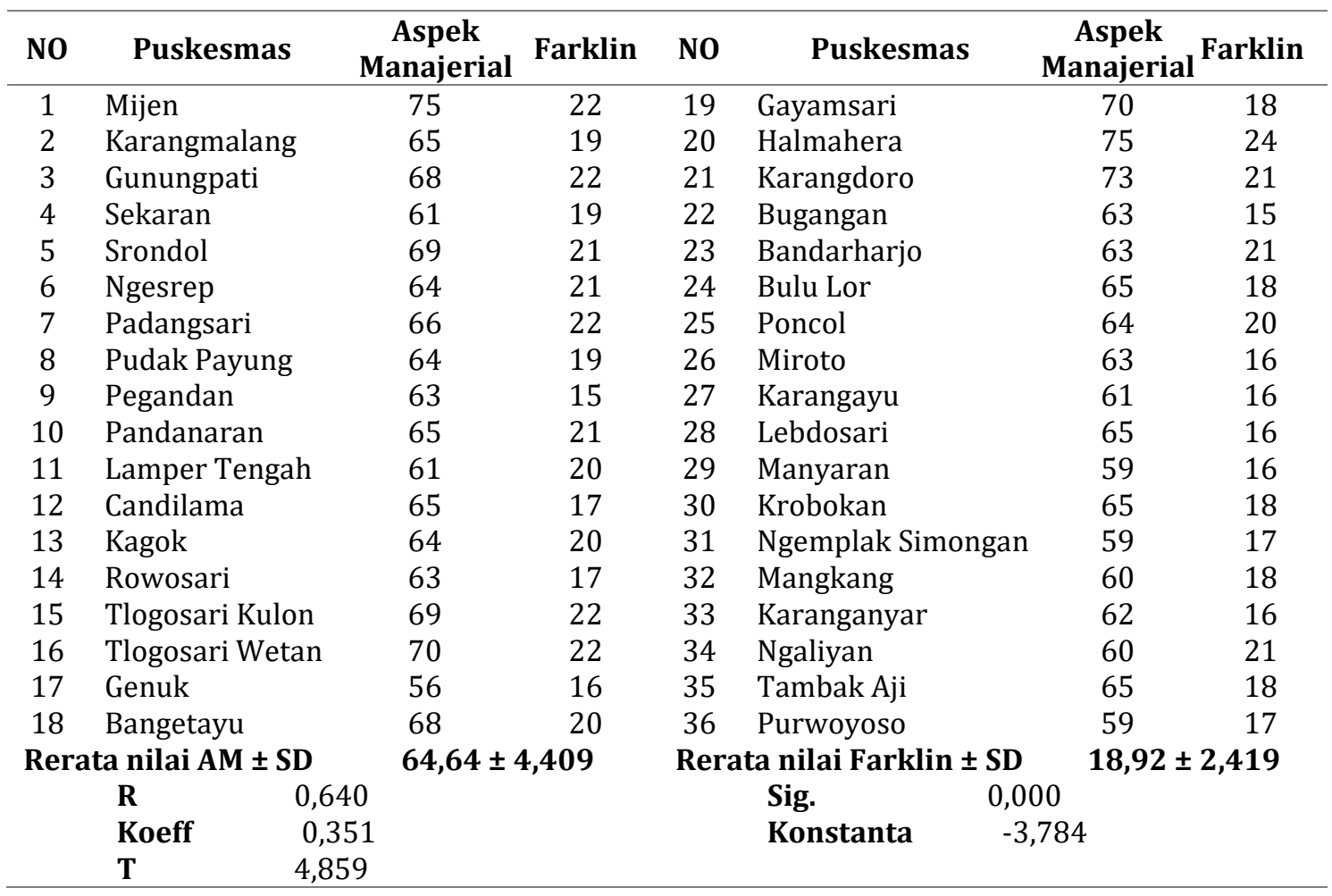

Keterangan : Sig = signifikasi

Tabel IV. Perbedaan Pelayanan Kefarmasian di Puskesmas Kota Semarang dilihat dari Faktor SDM Farmasi Tahun 2018

\begin{tabular}{lcc}
\hline SDM Farmasi & Rata-rata Nilai Yanfar \pm SD & $\begin{array}{c}\text { Uji Independent Sample } \\
\text { T-Test (Sig.2-tailed) }\end{array}$ \\
\hline Apoteker $(\mathrm{n}=16)$ & $88,44 \pm 5,549$ & \\
TTK $(\mathrm{n}=20)$ & $79,56 \pm 3,360$ & 0,000 \\
\hline
\end{tabular}

Keterangan : $\mathrm{n}=$ Frekuensi

demikian terdapat perbedaan peran SDM farmasi dalam pelayanan kefarmasian di Puskesmas Kota Semarang. Hal ini sejalan dengan penelitian (Rahmawati dkk., 2018) menyatakan bahwa pelayanan kefarmasian di Puskesmas PONED lebih baik dari pada tenaga teknis kefarmasian.

Sumber keuangan Puskesmas berasal dari berbagai sumber, salah satunya adalah dana kapitasi. Alokasi Dana Kapitasi untuk pembayaran dukungan biaya operasional pelayanan kesehatan dimanfaatkan untuk biaya obat, alat kesehatan, dan bahan medis habis pakai; dan biaya operasional pelayanan kesehatan lainnya. Selain itu, pemanfaatan anggaran untuk promosi layanan farmasi merupakan faktor pendukung implementasi pelayanan farmasi klinik. "External support from government was perceived as crucial to promoting pharmacy services. It is proposed that the internationally recognized Basel Statements of the International Pharmaceutical Federation also provide a strong foundation for guiding China in implementing clinical pharmacy services" (Penm dkk., 2014).

Nilai signifikasi yang diperoleh lebih dari probabilitas 0,05 dengan demikian tidak terdapat perbedaan pelayanan kefarmasian di Puskesmas Kota Semarang berdasarkan ketersediaan Anggaran untuk pendidikan dan 
Tabel V. Perbedaan Pelayanan Kefarmasian di Puskesmas Kota Semarang dilihat dari Ketersedian Anggaran Farmasi Klinik Tahun 2018

\begin{tabular}{lcc}
\hline Anggaran & Rata-rata Nilai Yanfar \pm SD & $\begin{array}{c}\text { Uji Independent Sample } \\
\text { T-Test (Sig.2-tailed) }\end{array}$ \\
\hline Ada $(\mathrm{n}=10)$ & $86,50 \pm 5,681$ & \\
Tidak $(\mathrm{n}=26)$ & $82,42 \pm 6,172$ & 0,079 \\
\hline
\end{tabular}

Keterangan $: \mathrm{n}=$ Frekuensi

Tabel VI. Perbedaan Pelayanan Kefarmasian di Puskesmas Kota Semarang dilihat dari Tipe Puskesmas Farmasi Tahun 2018

\begin{tabular}{lcc}
\hline Tipe & Rata-rata Nilai Yanfar \pm SD & $\begin{array}{c}\text { Uji Independent Sample } \\
\text { T-Test (Sig.2-tailed) }\end{array}$ \\
\hline RI $(n=11)$ & $88,82 \pm 6,493$ & \\
RJ $(n=25)$ & $81,24 \pm 4,576$ & 0,000 \\
\hline
\end{tabular}

Keterangan : $\mathrm{n}=$ Frekuensi; RI = Rawat Inap; RJ = Rawat Jalan

Tabel VII. Penentuan Skala Prioritas Penanganan Masalah untuk Pelayanan Kefarmasian di Puskesmas Kota Semarang Tahun 2018

\begin{tabular}{|c|c|c|c|c|c|c|c|}
\hline \multirow{3}{*}{ Kegiatan } & \multirow{3}{*}{$\begin{array}{c}\text { Daftar } \\
\text { Masalah }\end{array}$} & \multicolumn{4}{|c|}{ Kriteria dan Bobot Maksimum } & \multirow{3}{*}{ BPRS } & \multirow{3}{*}{$\begin{array}{c}\text { Prioritas } \\
\text { Masalah }\end{array}$} \\
\hline & & $\mathbf{A}$ & $\mathbf{B}$ & $\mathbf{C}$ & D & & \\
\hline & & $\begin{array}{c}\text { Besar } \\
\text { Masalah }\end{array}$ & $\begin{array}{c}\text { Keseriusan } \\
\text { Masalah }\end{array}$ & $\begin{array}{c}\text { Keefektifan } \\
\text { Solusi }\end{array}$ & PEARL & & \\
\hline Aspek & A1 & 10 & 10 & 10 & 1 & 66,67 & 5 \\
\hline \multirow[t]{3}{*}{ Manajerial } & A2 & 15 & 15 & 15 & 1 & 150 & 1 \\
\hline & A3 & 10 & 15 & 15 & 1 & 150 & 2 \\
\hline & A4 & 12 & 7 & 15 & 1 & 95 & 3 \\
\hline Pelayanan & B1 & 10 & 10 & 10 & 1 & 66,67 & 5 \\
\hline \multirow[t]{2}{*}{ Farmasi Klinik } & B2 & 5 & 7 & 5 & 1 & 20 & 6 \\
\hline & B3 & 5 & 7 & 5 & 1 & 20 & 6 \\
\hline $\begin{array}{l}\text { Ketersediaan } \\
\text { Anggaran }\end{array}$ & $\mathrm{C}$ & 10 & 14 & 10 & 1 & 80 & 4 \\
\hline
\end{tabular}

Keterangan: A: skor 0-10; B: skor 0-20; C: skor 0-10; D: skor 0 = Tidak; 1 =Ya

pelatihan farmasi klinik serta pengadaan tenaga farmasi. pelaksana layanan farmasi harus melakukan pelatihan untuk meningkatkan keterampilan dan sikap untuk menangani pasien.

Ketersediaan tenaga kefarmasian lebih ditentukan antara lain oleh lokasi puskesmas yaitu daerah perkotaan dan daerah tidak terpencil yang memiliki jumlah Apoteker dan TTK lebih banyak dibanding daerah lainnya. Demikian pula Puskesmas perawatan memiliki jumlah Apoteker dan TTK yang lebih banyak daripada puskesmas non-perawatan (Herman dkk., 2013). Hal tersebut juga terjadi di Kota Semarang, Apoteker diutamakan untuk Puskesmas Rawat Inap sehingga mempengaruhi pelayanan kefarmasian yang diberikan. Terdapat perbedaan pelayanan kefarmasian di Puskesmas Kota Semarang berdasarkan Tipe Puskesmas (Rawat Inap dan Rawat Jalan) dengan nilai signifikasi $0,000<0,05$. Hal ini berhubungan dengan ketersediaan atau penempatan Apoteker lebih diutamakan untuk Puskesmas Rawat Inap.

Penelitian ini terbatas pada peranan SDM farmasi (Apoteker atau TTK), ketersediaan anggaran pelayanan farmasi klinik dan tipe Puskesmas (Rawat inap atau Rawat jalan) dalam pelayanan kefarmasian Puskesmas di Kota Semarang, sehingga perlu dilakukan kajian analisis beban kerja farmasi di Puskesmas dan Seksi Kefarmasian dan Perbekalan Kesehatan 
Dinas Kesehatan Kota Semarang terhadap implementasi pelayanan kefarmasian di Puskesmas.

Faktor-faktor yang mendukung pelayanan kefarmasian Puskesmas di Kota Semarang adalah dukungan dari Kepala Puskesmas, koordinasi yang baik antara karyawan di Puskesmas dan Dinas. Faktorfaktor yang menghambat adalah apoteker belum tersedia di semua Puskesmas dan kurangnya pelatihan untuk tenaga farmasi dalam pelayanan farmasi klinik. Solusi yang dapat digunakan untuk mengatasi masalah pelayanan kefarmasian Puskesmas di Kota Semarang yaitu perbaikan sarana dan prasarana dengan penambahan ruang penyimpanan bahan berbahaya/ mudah terbakar dan gas medik, menyediakan ruangan khusus untuk konseling farmasi, membuat SOP pelayanan farmasi klinik, Puskesmas diharapkan menyediaan Anggaran untuk pengadaan Apoteker, pendidikan dan pelatihan farmasi klinik bagi tenaga kefarmasian, mengusulkan dan memenuhi kebutuhan Apoteker baik melalui seleksi CPNS dan/atau BLUD, Dinas Kesehatan Kota Semarang melakukan pembinaan SDM farmasi di Puskesmas secara rutin dan berkesinambungan, terkait pedoman dan manajemen pelayanan kafarmasian Puskesmas.

\section{KESIMPULAN}

Semua Puskesmas Kota Semarang sudah melakukan kegiatan pengelolaan sediaan farmasi dan BMHP (Aspek manajerial). Pelayanan farmasi klinik sudah dilakukan oleh apoteker dan tenaga teknis kefarmasian walaupun belum sepenuhnya. Terdapat perbedaan yang signifikan peran SDM farmasi dan tipe Puskesmas dalam pelayanan farmasi klinik Puskesmas di Kota Semarang. Tidak terdapat perbedaan yang signifikan ketersediaan anggaran terhadap pelayanan kefarmasian. Hasil uji regresi linier menunjukan bahwa aspek menejerial juga berpengaruh pada pelayanan farmasi klinik Puskesmas di Kota Semarang.

\section{UCAPAN TERIMA KASIH}

Terima kasih penulis sampaikan kepada Tuhan Yang Maha Esa, Badan PPSDM Kemenkes RI, Dinas Kesehatan Provinsi Jawa Tengah, Dinas Kesehatan Kota Semarang, Puskesmas Kota Semarang, Bapak Ibu dosen pembimbing dan penguji atas izin, bantuan dan masukan yang sudah diberikan kepada penulis untuk kesempurnaan penulisan jurnal. Studi ini dilakukan guna memenuhi persyaratan kelulusan program studi magister manajemen di fakultas Farmasi Universitas Gadjah Mada

\section{DAFTAR PUSTAKA}

Daulay, E.H., Oviani, G.A., Erlianti, K., Fudholi, A., dan Ayu, D., 2018. Analisis Kinerja Apoteker dan Faktor Yang Mempengaruhi Pada Era Jaminan Kesehatan Nasional di Puskesmas. Journal of Management and Pharmacy Practice, 8: 7.

Hanggara, R.S.L., Gibran, N.C., Kusuma, A.M., dan Galistiani, G.F., 2017. Pengaruh Keberadaan Apoteker terhadap Mutu Pelayanan Kefarmasian di Puskesmas Wilayah Kabupaten Banyumas. Jurnal Kefarmasian Indonesia, 7:

Hendri, D., Satibi, S., dan Endarti, D., 2018. Evaluation of Pharmaceutical Service and Management of Drug, Disposable Medical Supply, and Medical Equipment for Poned of Brebes Regency. Journal of Management and Pharmacy Practice, 8: 1.

Herman, M.J., Supardi, S., dan Yuniar, Y., 2013. Relationship of The Availability of Phamacist with Characteristics of Primary Health Center and Pharmacy Practice in Health Center. Buletin Penelitian Sistem Kesehatan, 16: 11.

Kemenkes RI, 2016. Permenkes Nomor 74 Tahun 2016 Tentang Perubahan Standar Pelayanan Kefarmasian Di Puskesmas. Kementerian Kesehatan RI, Jakarta.

Khalaf Ahmad, A.M., Alghamdi, M.A.S., Alghamdi, S.A.S., Alsharqi, O.Z., dan Al-Borie, H.M., 2016. Factors Influencing Patient Satisfaction with Pharmacy Services: An Empirical Investigation at King Fahd Armed Forces Hospital, Saudi Arabia. International Journal of Business and Management, 11: 272.

Lestari, T.R.P., 2014. Analisis Ketersediaan Tenaga Kesehatan di Puskesmas Kota Mamuju Provinsi Sulawesi Barat Tahun 2014. Kajian, 21: 14.

Mulyagustina, M., Wiedyaningsih, C., dan Kristina, S.A., 2017. Implementation of Pharmaceutical Care Standard in Jambi City's Pharmacies. Jurnal Manajemen Dan Pelayanan Farmasi Uournal of Management and Pharmacy Practice), 7: 
83.

Penm, J., Moles, R., Wang, H., Li, Y., dan Chaar, B., 2014. Factors Affecting the Implementation of Clinical Pharmacy Services in China. Qualitative Health Research, 24: 345-356.

Quick, J., Rankin, J, R., dan O'Cornor, 2012. Managing Drug Supply, The Selection, Procurement, Distribution and Use of Pharmaceutical, 3th Edition. USA: Kumarin Press, Conecticut.
Rachmawati, E., 2018. 'Evaluasi Peran Tenaga Kefarmasian Dalam Pelayanan dan Pengelolaan Obat, BMHP dan Alkes Program PONED di Puskesmas Kota Semarang', , Tesis, . Universitas Gadjah Mada, Yogyakarta.

Rahma, A., Arso, S.P., dan Suparwati, A., 2015. Implementasi Fungsi Pokok Pelayanan Primer Puskesmas Sebagai Gatekeeper Dalam Program JKN (Studi Di Puskesmas Juwana Kabupaten Pati). Jurnal Kesehatan Masyarakat, 3: 11. 